\title{
UM OLHAR COMPARADO SOBRE POLÍTICAS DE INCLUSÃO NAS ESCOLAS DE EDUCAÇÃO BÁSICA EM CARIACICA (ES)
}

\author{
Denise Meyrelles de Jesus ${ }^{1}$ iD \\ Sônia Aparecida Alvarenga Vieira ${ }^{1}$ \\ Karolini Galimberti Pattuzzo Breciane ${ }^{\text {(DD }}$ \\ Alexandro Braga Vieira ${ }^{1}$ D
}

RESUMO: Este trabalho apresenta uma perspectiva de estudos comparados em políticas públicas de Educação Especial das redes públicas de ensino de Cariacica (ES). Dialoga com a legislação vigente, com autores que discutem políticas educacionais e com o aporte da Sociologia do Conhecimento, de Souza Santos (2008). As análises abarcam as equipes centrais, a identificação dos alunos e os serviços disponíveis. Ao olhar comparativamente as políticas de Educação Especial das redes públicas de ensino, encontram-se similaridades e especificidades atravessando o processo de inclusão escolar dos alunos.

Palavras-chave: Educação especial. Inclusão escolar. Políticas em ação.

\section{A comparative look at policies of inclusion in basic education schools in Cariacica, ES, Brazil}

ABSTRACT: The present study presents a perspective of comparative studies regarding public policies of Special Education. The study was conducted at the public network

${ }^{1}$ Universidade Federal do Espírito Santo - Vitória (ES), Brasil. E-mails: jesusdenise@hotmail.com, soniaalvarengav@hotmail.com, karolinipattuzzo@hotmail.com, allexbraga@hotmail.com DOI: 10.1590/CC0101-32622018197631 
of Cariacica-ES. It dialogues with the current legislation, with authors who discuss educational policies and with the contribution of Sociology of Knowledge of Souza Santos (2008). The analyzes include the public educational system's work team, the processes of identifying students and services available to them, in an inclusive perspective. When comparing the Special Education policies of the public education networks, similarities and specificities are found through students' inclusion process.

Keywords: Special education. School inclusion. Policies in action.

\section{INTRODUÇÃO}

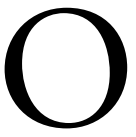

objetivo deste artigo é discutir a Educação Especial em uma perspectiva inclusiva com um olhar comparado. Analisamos as políticas nacionais e como estas se circunscrevem nos territórios locais, ou seja, como se materializam em açóes. Nosso olhar comparado recai sobre "procedimentos comparativos renovados que buscam rastrear a singularidade dos fenômenos sem perder de vista suas relaçóes com a conjuntura social mais ampla" (REZENDE; ISOBE; MOREIRA, 2013, p. 231), portanto, um olhar qualitativo, que nos permite acompanhar os movimentos da escolarização dos alunos público-alvo da Educação Especial em diferentes cenários, de forma a "identificar continuidades e descontinuidades, estabelecer similaridades e diferenças entre realidades observáveis de um determinado fenômeno" (REZENDE; ISOBE; MOREIRA, 2013, p. 231). Assim, concordamos com Barroso (2009, p. 10) quando argumenta que devemos "definir a comparabilidade não como um pressuposto adquirido, mas como um processo de construção daquilo que é comparável". É importante sinalizar que o ato de comparar pressupóe considerar os fatores que atravessam as políticas, tornando-as exequíveis ou de difícil implementação.

No caso da Educação Especial, entre muitas outras questóes, temos nos perguntado recentemente sobre a estrutura organizativa das Secretarias de Educação: qual o fluxo de matrícula de alunos 
com deficiência, com transtornos globais do desenvolvimento e altas habilidades/superdotação? Quais os serviços de apoio especializado? Como ocorre o processo de identificação dos alunos? Como e quais profissionais estão disponíveis?

Nosso estudo geral tem por objetivo cartografar a Educação Especial em espaços locais de três Estados brasileiros (Espírito Santo, Rio Grande do Sul e São Paulo), bem como entender tais questóes em três países também envolvidos na pesquisa (México, Moçambique e Itália) para procedermos à comparação.

Neste artigo, apresentamos um recorte, assumimos o espaço local de Cariacica, município da regiáo metropolitana de Vitória, como espaço de análise, buscando realizar um estudo comparado entre a rede estadual de ensino e a municipal, no que se refere à implementação de políticas públicas de Educação Especial. Tivemos como participantes da pesquisa membros da equipe gestora municipal de Educação Especial, bem como da Superintendência Regional de Educação (SRE) da rede estadual de educação no município. Na rede municipal, foi possível dialogar também com professores e familiares de alunos público-alvo da Educação Especial matriculados no município. Lançamos mão, como ferramentas principais de informaçôes, de grupos focais e entrevistas semiestruturadas. Também trouxemos à tona índices educacionais do território. No processo de análise, dialogamos as informaçóes entre si e as narrativas foram analisadas tanto pela via da análise de conteúdo quanto da análise do discurso.

\section{UM OLHAR COMPARADO ENTRE A REDE ESTADUAL E A MUNICIPAL DE ENSINO EM CARIACICA (ES)}

Para entender os processos de escolarização de alunos público-alvo da Educação Especial, adotamos um conjunto de eixos de análise/comparação que nos permitem compreender as açóes políticas e pedagógicas direcionadas a tal objetivo. Esses eixos são apresentados em tópicos, visando permitir ao leitor compreender cada realidade pesquisada e seus pontos de intercessão e singularidades. 


\section{A ESTRUTURA ORGANIZATIVA DAS REDES DE ENSINO ANALISADAS}

A rede estadual de ensino se organiza geograficamente em um órgão centralizado - Secretaria de Estado da Educação (Sedu) - e tem como ramificação 11 SREs localizadas em regiōes administrativas. Todas contam com um setor de diversidade/inclusão. Uma das SREs está localizada no município de Cariacica, tendo nela incluída a Equipe de Educação Juventude e Diversidade, constituída por um profissional que responde pela Educação do Campo, outro pela educação de jovens e adultos (EJA) e presídios (Instituto de Atendimento Socioeducativo do Espírito Santo - Iases) e três dedicados à Educação Especial, tendo em vista a demanda dessa regional que, para além do município de Cariacica, assessora ainda mais dois municípios de menor porte.

Em contrapartida, a rede municipal de ensino tem estruturada a Secretaria Municipal de Educação (Seme) e possui a Coordenação de Diversidade e Inclusão Educacional (CDI), cujo foco é a Educação Especial, as questóes étnico-raciais, as de gênero e as de diversidade sexual. No ano de 2016, a equipe foi composta de seis profissionais que possuem formação em Pedagogia, com especialização em Educação Especial, e uma com formação nas questóes raciais e de diversidade.

Uma primeira relação comparativa que podemos realizar é que ambas possuem um setor responsável por lidar com a implementação de políticas públicas para a diversidade/diferença humana, fazendo parte dessa dinâmica a Educação Especial. Conforme analisado por Vieira (2018), a organicidade de ambas as Secretarias de Educação analisadas parece receber influências da estrutura organizativa do Ministério da Educação, que também conta com um setor destinado a pensar políticas públicas para a diversidade, náo dispondo de um órgão específico para a Educação Especial. A nosso ver, tal cenário traz desafios que precisam ser considerados, entre eles a necessária articulação da equipe que compóe o setor para que as demandas de um determinado grupo social não venham suplantar as do outro. Como as questóes que envolvem a Educaçáo Especial se colocam bem expressivas, faz-se necessária a reflexão clara com as unidades escolares para que os alunos atendidos pelo setor não venham a ser considera- 
dos públicos-alvo da Educação Especial, situação muito rotineira no trato que a escola dá à diversidade/diferença humana.

Entender a estruturação de funcionamento das duas redes de ensino nos permite também conhecer a história das políticas de Educação Especial no município estudado. Nos casos da rede estadual e da municipal, ambas trazem um histórico comum marcado pelas instituiçóes especializadas e pela criação das classes especiais nas escolas comuns para atendimento aos alunos. Embora ainda haja o funcionamento dessas instituiçôes ${ }^{1}$, o fechamento das classes especiais e a sua transformação em salas de recurso se colocou como um marco para se pensar as políticas públicas estaduais e municipais para a inclusão dos estudantes na sala de aula comum.

Esse acontecimento foi sustentado pela Constituição Federal de 1988 (BRASIL, 1988) e pela Lei de Diretrizes e Bases da Educação Nacional no 9.394/96 (BRASIL, 1996), bem como pela Política Nacional de Educação Especial na Perspectiva da Educação Inclusiva (BRASIL, 2008), documento determinante no estabelecimento do acesso às classes comuns do ensino regular aos alunos público-alvo da Educação Especial em oposição à situação anterior de classes especiais.

Com esses direcionamentos, fez-se necessário detalhar orientações normativas acerca dos atendimentos da Educação Especial às escolas regulares. No caso da rede estadual de ensino, foram publicadas as Diretrizes da Educação Especial na Educação Básica e Profissional do Espírito Santo (2010), para a Rede Estadual de Ensino, e a Resoluçáo no 2.152/2010 (CONSELHO ESTADUAL DE EDUCAÇÃO DO ESPÍRITO SANTO, 2010), que dispóem sobre a Educação Especial no sistema estadual de ensino.

Além disso, a rede de ensino compôs a Resolução no 2.152/2010, que regulamentou/criou os Centros de Atendimento Educacional Especializado (CAEEs), localizados nas instituiçóes especializadas para a oferta do Atendimento Educacional Especializado (AEE) no contraturno. É relevante destacar a Lei Estadual no 9.620/2011, que assegura "o direito à matrícula às pessoas com deficiência nas escolas públicas estaduais mais próximas de suas residências, independentemente da existência de vagas ou de lista de reserva" (ESPÍRITO SANTO, 2011, p. 9). 
Esse movimento estadual, em consonância com o movimento nacional, é relatado por Pantaleão (2012, p. 16), quando assim sinaliza:

Nos últimos anos, a Secretaria Estadual de Educação vem diagnosticando a realidade educacional da Educação Especial do Estado do Espírito Santo, seja por meio de estudos com ênfase nas políticas públicas, seja por situações mais pontuais, com ênfase nas açóes e práticas no intuito de melhor qualificar os serviços que ali são oferecidos bem como na tentativa de garantir que tais serviços ocorram em consonância com as políticas vigentes no que se refere às pessoas em situação de deficiência.

O caminho normativo adotado pela rede municipal é similar ao da rede estadual que, por historicamente ser o maior sistema de ensino, acabou por influenciar muitas políticas municipais (VIEIRA, 2018). Com o fechamento das classes especiais, a rede municipal também passa a compor um conjunto de documentos normativos, visando orientar a Educação Especial. Com isso, criou-se a Resolução no 4/2006, que especifica que "a escola regular, de qualquer nível ou modalidade de ensino, deverá promover a organização de classes comuns e de serviços de apoio pedagógico especializado" (PREFEITURA DE CARIACICA, 2006), definindo, assim, o lócus de matrícula dos alunos público-alvo da Educação Especial como sendo as escolas comuns.

Em 2008, implementa a Resolução no 31/2008, na qual cria o Sistema Municipal de Ensino da Educação Básica (PREFEITURA DE CARIACICA, 2008). Nesse segundo bloco de análise comparativa, percebemos que a estrutura organizativa, a história da Educação Especial e a constituição de documentos normativos das duas redes de ensino analisadas parecem se traduzir (SOUZA SANTOS, 2008) uma na outra. Segundo Souza Santos (2008, p. 127), “a tradução é um movimento intelectual e político" que pode possibilitar a análise de outros pontos de vista e a produção de novas/outras significaçóes pelo reconhecimento local. Há grande proximidade, fazendo-nos perceber que uma esfera apreende/implica as políticas públicas da outra, sem desconsiderar os ordenamentos federais, que também condicionam o processo. 


\section{O FLUXO DE MATRÍCULA, OS PROFISSIONAIS ESPECIALIZADOS E OS SERVIÇOS DE APOIO}

Com relação ao fluxo de matrícula, encontramos algumas similaridades, bem como especificidades. $\mathrm{O}$ número de matrícula de alunos público-alvo da Educação Especial no Estado e no município - conforme Censo Escolar das Escolas de Educação Básica do Espírito Santo (ESPÍRITO SANTO, 2015) — pode ser visualizado na Tabela 1.

Tomando como ponto de análise comparativa a matrícula dos alunos entre as redes, entendemos que a rede municipal conta uma demanda sempre superior à rede estadual. Isso nos faz perceber que, embora a estadual atenda também ao ensino fundamental (além do ensino médio e da educação profissional), a maior matrícula de alunos público-alvo da Educação Especial ainda se concentra na educação infantil e no ensino fundamental municipais. Com isso, podemos também inferir que o ingresso no ensino médio ainda é bastante tímido. Com relação ao fluxo, ele segue o seguinte caminho: em 2007 e 2008, há crescimento,

\section{Tabela 1}

Número de alunos público-alvo da Educação Especial matriculados na rede regular de ensino no Espírito Santo.

\begin{tabular}{lccccc}
\hline Ano & Estadual & Federal & Municipal & Privada* $^{*}$ & Total \\
\hline 2007 & 1.150 & 2 & 5.917 & 406 & 7.475 \\
\hline 2008 & 1.706 & 3 & 9.635 & 514 & 11.858 \\
\hline 2009 & 1.387 & 4 & 5.876 & 433 & 7.700 \\
\hline 2010 & 2.611 & 12 & 10.659 & 581 & 13.863 \\
\hline 2011 & 3.245 & 14 & 10.069 & 512 & 13.840 \\
\hline 2012 & 3.830 & 51 & 12.739 & 739 & 17.359 \\
\hline 2013 & 4.183 & 72 & 13.175 & 744 & 18.174 \\
\hline 2014 & 4.879 & 90 & 14.248 & 749 & 19.966 \\
\hline 2015 & 5.359 & 108 & 15.885 & 805 & 22.157 \\
\hline
\end{tabular}

*Informamos que, no Espirito Santo, os CAEEs localizados nas instituiçōes filantrópicas não ofertam ensino regular, e sim atendimento educacional especializado no contraturno. Sendo assim, a rede privada refere-se às escolas de ensino fundamental e médio da rede particular.

Fonte: Secretaria de Estado da Educação do Espirito Santo (2015). 
bem como queda, em 2009, em ambas as redes. Em 2011, há uma diminuição na rede municipal e o aumento se mantém nos anos subsequentes nas duas esferas analisadas.

Vieira (2018) argumenta que o aumento da matrícula na escola regular evidencia que tanto a rede estadual quanto a municipal passaram a criar outras relaçóes com as instituiçóes especializadas, pois se, por muito tempo, tal espaço-tempo concentrava a matrícula dos alunos, agora, com a Política Nacional de Educação Especial na Perspectiva da Educação Inclusiva (BRASIL, 2008), as redes necessitam estabelecer uma relação de "complementaridade" com as escolas comuns, tendo em vista $\mathrm{o}$ atendimento educacional especializado não poder ser substitutivo do currículo comum. Cabe ressaltar outra comparação: as duas redes analisadas se colocaram (e de certa forma ainda assim se colocam) como financiadoras de muitas ações das instituições especializadas na relação público-privado (contratos, repasse de subvenções, cessão de profissionais, entre outras), conforme sinalizado no estudo de Laplane, Caiado e Kassar (2016).

Ainda em relação à matrícula, todas as redes de ensino possuem alunos com diversificadas condiçóes: cegos/baixa visão, autistas, surdos/deficiência auditiva, altas habilidades/superdotação, deficiência física, entre outras. A deficiência intelectual é a condição que mais sobressai (alguns alunos com laudo e outros sem). Essa última informação fala de certa tensão vivida nas escolas na definição dos alunos público-alvo da Educação Especial, pois todas as "dificuldades de aprendizagem" são trazidas para a categoria "deficiência intelectual", situação que pode ser influenciada pela composição do órgão central, que tem a tarefa de pensar políticas para a diversidade/diferença humana de maneira ampla.

Pensar no fluxo de matrícula de alunos nas redes de ensino analisadas nos leva a analisar a constituição dos serviços de apoio especializado. Nas escolas estaduais, podemos perceber a contratação de um professor de Educação Especial (de acordo com as necessidades dos alunos) para atendimento nas salas de recursos multifuncionais (SRMs) e para a realização do trabalho colaborativo em sala de aula. Contratam-se professores especializados nas áreas específicas de atendimento - cegueira, surdez, deficiência intelectual, transtornos globais do desenvolvimento e altas habilidades/superdotação. $\mathrm{Na}$ área de deficiência visual, além do 
atendimento educacional especializado e do trabalho colaborativo realizado pelo professor especializado, a rede estadual de ensino implantou o Centro de Atendimento Pedagógico à Pessoa com Deficiência Visual (CAP), em parceria com o Governo Federal. Esse centro realiza, entre outras atividades, formação continuada para professores e produção de livros digitais e em braille para toda a rede pública de ensino. De forma similar, na rede municipal, o atendimento educacional especializado acontece nas SRMs que têm por foco a deficiência visual, garantindo também a produção do material pedagógico em braille.

Agora, fazendo uma análise da rede municipal, percebemos a existência de encaminhamentos políticos diferentes para os serviços de apoio à escolarização dos alunos. As escolas municipais contam com dois professores especialistas: o professor colaborador das açóes inclusivas e o professor do AEE. O primeiro atua em uma única escola com o objetivo de colaborar com o processo de inclusão dos alunos em sala de aula e, quando possível, realiza intervençóes pedagógicas também com outros alunos que apresentam algum tipo de necessidade educacional especial. O segundo possui formação específica de acordo com as condições dos grupos de alunos que atende e realiza suas açóes nas SRMs, no contraturno. Periodicamente, executa visitas pedagógicas às escolas dos alunos que estão matriculados em outras unidades de ensino, com o objetivo de planejar com os professores regentes e pedagogos e orientar a escola quando necessário.

A rede estadual conta com 264 profissionais envolvidos com a Educação Especial com diferentes áreas de formação/atuação, e a rede municipal, com 464 profissionais. Quanto aos alunos surdos matriculados na rede estadual, eles ainda contam com atendimentos específicos do tradutor e intérprete de libras e do instrutor de libras. $\mathrm{O}$ intérprete trabalha em sala de aula na tradução e interpretação e o instrutor, na sala de recursos com o ensino da língua brasileira de sinais.

Para atendimento aos alunos no contraturno, as redes de ensino analisadas/comparadas contam com um número interessante de SRMs. Vejamos, por exemplo, a rede municipal, cujos dados estáo na Tabela 2.

Podemos notar, na Tabela 2, que é significativo o número de escolas municipais com essas salas, as quais, em sua grande maioria, foram 
equipadas pelo Programa de Implantação de Salas de Recursos Multifuncionais do MEC. A rede estadual (Tabela 3) também apresenta essa mesma política, ou seja, a constituição das salas de recursos para atendimento no contraturno. Algumas escolas estão indicadas no programa, mas ainda não receberam os equipamentos ${ }^{2}$, e outras têm atendimento, no entanto eles ocorrem em diversos espaços da escola. "Quando não tem salas de recursos, os alunos são atendidos no laboratório de informática, na biblioteca" (DIÁRIO DE CAMPO, TÉCNICA MARIA, SRE Cariacica).

Além da contratação de professores especializados, as duas redes de ensino trazem em seu quadro funcional a presença de profissionais de apoio para atender aos estudantes com maiores comprometimentos em atividades de alimentação, locomoçáo e higienização. A partir de 2009, a rede estadual de ensino passou a contratar profissionais denominados "cuidadores".

\section{Tabela 2}

Salas de recursos multifuncionais na rede municipal.

\begin{tabular}{l|c|c|c|c|c|c|c}
\hline Rede Municipal & $\mathbf{2 0 1 0}$ & $\mathbf{2 0 1 1}$ & $\mathbf{2 0 1 2}$ & $\mathbf{2 0 1 3}$ & $\mathbf{2 0 1 4}$ & $\mathbf{2 0 1 5}$ & $\mathbf{2 0 1 6}$ \\
\hline $\begin{array}{l}\text { Escolas que } \\
\text { possuem SRM }\end{array}$ & 4 & 9 & 15 & 21 & 25 & 25 & 28 \\
\hline
\end{tabular}

SRM: salas de recursos multifuncionais.

Fonte: Secretaria Municipal de Educação (2016).

\section{Tabela 3}

Salas de recursos multifuncionais na rede estadual.

\begin{tabular}{l|c}
\hline Instituiçóes & Rede Estadual \\
\hline Escolas com SRM/MEC & 30 \\
\hline Escolas com SRM/MEC — sem equipamentos & 15 \\
\hline Escolas com AEE em outros espaços & 9 \\
\hline Escolas que não apresentaram demanda & 63 \\
\hline Total de escolas & 9 \\
\hline
\end{tabular}

SRM: sala de recursos multifuncionais; AEE: atendimento educacional especializado. Fonte: Secretaria Municipal de Educação (2016). 
Vale ressaltar que, na rede municipal, ocorre a contratação de estagiários ${ }^{3}$ para atuar na função de "cuidadores"/apoios pedagógicos, visando auxiliar também os alunos que demandam apoio na alimentação, locomoção e higienização. Nas duas redes de ensino, muitas vezes, os "cuidadores" são subjetivados (pelas escolas) como os responsáveis pela escolarização desses alunos, situação que nos leva a perceber o quanto os gestores, os profissionais especializados, os coordenadores e os professores regentes de classe ainda precisam se considerar parte desse processo.

Temos, nesse eixo, várias possibilidades comparativas:

- a preocupação com a constituição de redes de apoio à sala de aula comum em ambos os sistemas de ensino;

- $\quad$ o atendimento educacional que é realizado, nas duas redes de ensino, no contraturno, consoante à Política Nacional de Educação Especial;

- a matrícula de alunos com especificidades "severas" que estão nas escolas dos sistemas de ensino aqui analisados/comparados;

- $\quad$ as tensóes nas redes de ensino no que se refere à presença de profissionais denominados "cuidadores", sem uma definição específica da formação que deveriam ter para exercer a função.

\section{OS PROCESSOS DE IDENTIFICAÇÃO DOS ALUNOS}

Outro elemento que compõe as políticas de Educação Especial nas redes analisadas é o processo de identificação dos alunos para acesso/ encaminhamento aos serviços de apoio especializado. Na rede municipal, a identificação acontece por meio de um levantamento realizado pelo pedagogo e pelo diretor, possuindo o aluno laudo médico ou não.

A partir desse levantamento, a equipe da Seme realiza assessoria à escola e determina o profissional para atuar na unidade de ensino. Para o atendimento no contraturno, o aluno é encaminhado pela equipe escolar para a SRM mais próxima (caso não haja na sua escola) e o professor especialista organiza o atendimento de acordo com as necessidades do aluno e a disponibilidade da família, podendo ser de duas a três vezes na semana. 
Esse modo de avaliação (realizado pela escola) ainda foi encontrado nos dados de um estudo denominado Observatório Nacional de Educação Especial, também realizado no Espírito Santo, que assim ressalta:

$\mathrm{Na}$ avaliaçáo de identificação, a maioria dos profissionais evidencia que, muitas vezes, mediante a ausência do diagnóstico clínico, um primeiro olhar avaliativo é realizado pelo professor da sala de aula comum. Esse primeiro olhar é permeado por queixas. Algumas relacionadas com o comportamento e outras com a apropriação do conhecimento [...]. Muitas vezes, pouco se problematizam as questóes levantadas pelo professor de sala de aula, "confirmando" a suspeita do desvio em relação à aprendizagem (JESUS et al., 2015, p. 333-334).

O estudo em tela aponta que muitas escolas encontram dificuldades de significar a inclusão escolar para além da Educação Especial, e isso gera certa preocupação entre os estudiosos da área: a produção da deficiência. Vivemos ainda, dentro da escola, a necessidade diagnóstica e classificatória determinando não somente os aspectos do indivíduo que serão trabalhados, mas também as atitudes e práticas educativas com relação a esses estudantes.

Trazendo a rede estadual para esse processo de análise/comparaçáo, cabe dizer que a identificação dos alunos ocorre por meio de laudo médico e/ou relatório pedagógico (produzido pela escola). Esses documentos são encaminhados para a Secretaria de Educação/SRE, para autorização da contratação do professor especializado.

Podemos realizar uma comparação entre as redes analisadas em relação ao diagnóstico: o laudo médico é um dado importante, mas não é condicionante para o atendimento ao aluno. Não podemos deixar de ressaltar que há elementos na identificação que se colocam como uma tensão tanto para a rede estadual quanto para a municipal (VIEIRA, 2018). Apesar de as redes tomarem como público-alvo os estudantes apontados pela Política Nacional de Educação Especial, em uma perspectiva inclusiva (estudantes com deficiência, transtornos glo- 
bais do desenvolvimento e altas habilidades/superdotação), há dúvidas nas escolas que atravessam o processo: o aluno com hiperatividade entra no atendimento? E aqueles com dislexia, dislalia, discalculia, entre outros? Podemos trabalhar com os alunos com dificuldades de aprendizagem/fracasso escolar? Concordamos com Jesus et al. (2015) que isso se dá, principalmente, pela inexistência de outras políticas públicas para atender a outros grupos sociais matriculados na escola comum. Para lidar com essas questóes, as equipes técnicas das redes estadual e municipal sempre medeiam as açóes/dúvidas das escolas no processo de identificação dos alunos.

\section{AS POLÍTICAS DE FORMAÇÃO CONTINUADA DE PROFESSORES}

O último eixo de análise/comparação se refere aos investimentos na formação continuada dos profissionais da educação. Percebemos potencialidades nas duas redes, no que se refere aos investimentos na formação continuada dos professores e dos gestores educacionais. Para Lüdke (2001, p. 5), o desenvolvimento profissional só poderá ser vivido num cenário que "articule intimamente teoria e prática educativas, num diálogo estreito com os sujeitos e as circunstâncias concretas de cada processo educacional e tendo em vista o aprimoramento da sociedade no seu conjunto".

$\mathrm{Na}$ rede municipal, os investimentos na formação docente vêm se dando de diferentes maneiras. Muitas açôes são organizadas pela Seme, outras são realizadas nas escolas e várias por meio de parcerias com universidades públicas (cursos de especializações, seminários, colóquios, entre outros). Os investimentos na formação de professores se colocam como uma política pública que vem se consolidando já por um longo período na rede municipal de ensino. Esse movimento, de acordo com Pantaleão (2012), parece ter contagiado os gestores educacionais (diretores e pedagogos), que assumem essa mesma postura nos cotidianos escolares, fomentando momentos de formação continuada na própria escola.

Os espaços-tempos de planejamento também parecem tentar ganhar uma conotação de formação docente, rompendo com linhas de raciocínio que colocam a formação continuada como espaços-tem- 
pos realizados somente por meio de palestras. Percebemos que, na rede municipal, os espaços de planejamento tentam ser vistos como oportunidades de encontros entre professores e coordenadores pedagógicos para que, neles, as escolas possam refletir sobre as trajetórias dos alunos e a necessidade de as práticas pedagógicas serem diversificadas. Para a rede municipal, uma conquista obtida é a garantia de planejamento quinzenal para os professores, convocando os coordenadores pedagógicos a se colocarem como articuladores e mediadores desses espaços-tempos.

No que tange à rede estadual, a orientação às escolas ocorre mais fortemente de maneira centralizada. A equipe, localizada na SRE Cariacica, realiza encontros formativos com os professores especializados que ocorrem por área de atendimento e por região. A equipe ainda participa de reunióes com coordenadores pedagógicos e diretores, discorrendo sobre a política de Educação Especial. A assessoria direta às escolas não se dá com frequência. Percebe-se que essas ações ficam sob a orientação e responsabilidade dos professores especializados, que estáo na unidade escolar com a participação de coordenadores pedagógicos e diretores, situaçáo que (como dito) difere um pouco da rede municipal.

Promovendo uma análise comparativa desse último eixo, podemos perceber que os investimentos na formação continuada se colocam como apostas das duas redes de ensino. No que se refere à assessoria às escolas, é possível notar que as redes de ensino trabalham com estratégias diferenciadas. No entanto, mesmo com várias dificuldades, há movimentos realizados pelos técnicos, pelos próprios professores e gestores, bem como por meio de parcerias com várias instituições, como a Universidade Federal do Espírito Santo.

Cabe finalizar esta análise comparativa concordando com Mainardes (2006, p. 53), quando aponta que "os professores e demais profissionais exercem um papel ativo no processo de interpretaçáo e reinterpretação das políticas educacionais e, dessa forma, o que eles pensam e no que acreditam tem implicaçóes para o processo de implementação das políticas". Encontramos em Cariacica (ES) — tanto na rede estadual quanto na municipal - profissionais que buscam, dentro de suas possibilidades, referendar o pressuposto trazido pelo autor, quando encontramos gestores escolares, pedagogos, professores de ensino comum e docentes especializados buscando compor políticas no interior das esco- 
las, bem como contribuindo/avaliando/ressignificando aquelas advindas das esferas nacional e local (estadual e municipal).

Vislumbramos esse movimento de reinterpretar e implementar a política de Educação Especial nas redes municipal e estadual de Cariacica, porém devemos considerar as condiçóes que existem em cada rede, reconhecendo que ambas apresentam possibilidades, mas também limitaçóes nas políticas públicas instituídas. Cabe destacar que os últimos dez anos, tanto em termos estadual quanto municipal, revelam um saldo positivo no campo do financiamento da Educação e Educação Especial; nas políticas de formação docente; e na implementação de serviços (com destaque para a instalação das salas de recursos multifuncionais e dos trabalhos em colaboração).

\section{CONCLUSÃO}

Tendo em vista que este estudo busca olhar a interioridade de determinadas realidades educacionais para promover a análise/comparação desta com outros contextos, nacionais e/ou internacionais, o presente texto, ao olhar comparativamente as políticas de Educação Especial nas redes estadual e municipal de Cariacica (ES), encontra similaridades e especificidades atravessando o processo.

Para Franco (1992, p. 14), estudos dessa natureza permitem o reconhecimento do outro e de si mesmo pelo outro, já que "a comparação é um processo de perceber as diferenças e semelhanças e de assumir valores nessa relação de mútuo reconhecimento. Trata-se de entender o outro a partir dele mesmo e, por exclusão, se perceber na diferença”.

Ancorados nos pressupostos dos estudos comparados, encontramos, nas duas redes de ensino analisadas, muitas implicaçóes das normatizaçốes nacionais, bem como de acordos internacionais sustentando as açóes implementadas na área de Educação Especial. Percebemos também muitas similitudes entre esses dois sistemas de ensino, principalmente no que se refere à composiçáo da equipe central, à história da Educação Especial e ao fluxo de matrícula dos alunos. Além disso, não podemos negar as especificidades que também atravessam o processo, 
principalmente quando olhamos para alguns serviços de apoio, as açóes dos professores especializados e o acompanhamento às escolas.

O saldo deste estudo comparado entre as duas redes de ensino é que, em Cariacica (ES), existem movimentos sendo constituídos, visando à garantia do direito à escolarização para os alunos com deficiência, transtornos globais do desenvolvimento e altas habilidades/superdotação. Essas políticas, no dizer de Souza Santos (2008), traduzem-se em vários momentos e têm respeitadas as suas singularidades.

Nem de longe o reconhecimento da Educação como direito de todos deixa de ser atravessado por desafios. Desafios são cotidianamente assumidos pelos profissionais que atuam nas duas redes analisadas/comparadas. Embora os investimentos financeiros estejam mais direcionados para a escolarização dos alunos nas escolas comuns, a relação público-privado ainda não se encontra superada; há desafios no processo de identificação dos alunos, relação de dependência para com os diagnósticos clínicos e produção de sujeitos com deficiência (dada a dificuldade de se estabelecerem diálogos entre os pressupostos da inclusão escolar e da educação especial); falta de espaços específicos para realização do atendimento educacional especializado em algumas unidades de ensino; necessidade de compreensão das atribuições de "cuidadores"/estagiários no processo de escolarização dos alunos; e assessorias mais sistematizadas do órgão central estadual.

Mesmo assim, podemos dizer que as redes de ensino buscam constituir uma visão de educação como direito social e as escolas de ensino comum como lócus de aprender na diferença. Com isso, novos significados são dados para os ambientes escolares, assumidos como um profícuo lócus de formação docente e de gestão dos processos de ensinar-aprender no contexto escolar, responsabilidade de todos os docentes, coordenação pedagógica e gestáo.

Esse novo olhar tem implicado na assunção do princípio da educabilidade de todos e da composiçáo de redes de colaboração entre professores do ensino regular e especializados, tendo como horizonte o direito de os alunos acessarem os conhecimentos sistematizados. Além dessas visóes, o estudo revela que as redes de ensino podem buscar tradução de novas/outras açóes/políticas, tendo em vista que uma pode 
colaborar e aprender com a outra, situação defendida pela Constituição Cidadá e pelos Planos de Educação amplamente debatidos em cenário nacional, estadual e municipal.

\section{REFERÊNCIAS}

BARROSO, J. Prefácio. In: . Educação comparada: rotas do além-mar. São Paulo: Xamã, 2009.

BRASIL. Constituição [da] República Federativa do Brasil. Brasília: Senado Federal, 1988.

. Lei no 9.394, de 20 de dezembro de 1996. Estabelece as diretrizes e bases da educação nacional. Diário Oficial [da] República Federativa do Brasil, Brasília, 23 dez. 1996. Disponível em: <http://www.planalto.gov.br/CCIVIL 03/Leis/ L9394.htm>. Acesso em: $1^{\circ}$ out. 2005.

- Manual de orientação: Programa de Implantação de Sala de Recursos Multifuncionais. Brasília: Ministério da Educação, 2010. Disponível em: $\quad$ http://portal.mec.gov.br/index.php?option=com docman \&view = download \&alias=9936- manual - orientacao - programaimplantacao-salas-recursos-multifuncionais $\&$ Itemid $=30192>$. Acesso em: 20 jul. 2015.

. Politica Nacional de Educação Especial na Perspectiva da Educação Inclusiva. Brasília: Ministério da Educação/Secretaria de Educação Especial, 2008.

CONSELHO ESTADUAL DE EDUCAÇÃO DO ESPÍRITO SANTO. Resoluçáo $n^{\circ}$ 2.152, de 7 de janeiro de 2010. Diário Oficial do Estado do Espírito Santo, Vitória, p. 23-26, 26 fev. 2010.

ESPÍRITO SANTO. Lei no 9.620, de 11 de janeiro de 2011. Diário Oficial do Espírito Santo, Vitória, 12 jan. 2011.

- Secretaria Estadual de Educação do Espírito Santo. Diretrizes da Educação Especial na Educação Básica e Profissional do Espírito Santo. Vitória: Secretaria Estadual de Educação do Espírito Santo, 2010.

- Censo Escolar das Escolas de Educação Básica do Espírito Santo. Vitória: Secretaria Estadual de Educação do Espírito Santo, 2015. 
FRANCO, M.C. Estudos comparados em educação na América Latina: uma discussão teórico-metodológica a partir da questáo do outro. In: (Org.). Estudos Comparados e Educação na América Latina. São Paulo: Cortez, 1992. p. 13-35. (Livros Tatu).

JESUS, D.M.; VIEIRA, A.B.; AGUIAR, A.M.; SOAVE, A.R.B. Avaliação em educação especial: diálogos sobre diagnóstico, planejamento e rendimento escolar nas salas de recursos multifuncionais. In: MENDES, E.G.; CIA, F.; D'AFFONSECA, S.M. (Orgs.). Inclusão escolar e a avaliação do público-alvo da educação especial. São Carlos: Marquezine \& Manzini/ABPEE, 2015. p. 327-348.

LAPLANE, A.L.F.; CAIADO, K.R.M.; KASSAR, M.C.M. As relaçôes públicoprivado na educação especial: tendências atuais no Brasil. Teias, Rio de Janeiro, v. 17, n. 46, p. 40-55, jul./set. 2016. https://doi.org/10.12957/teias.2016.25497

LÜDKE, M. O professor e a pesquisa. São Paulo: Papirus, 2001.

MAINARDES, J. Abordagem do ciclo de políticas: uma contribuição para análise de políticas educacionais. Educação e Sociedade, Campinas, v. 27, n. 94, p. 47-69, jan./abr. 2006. http://dx.doi.org/10.1590/S0101-73302006000100003

PANTALEÃO, E. Política e gestão da educação especial em foco. In: JESUS, D.M. (Org.). Gestão da educação especial: pesquisa, política e formação. Curitiba: Appris/Secretaria de Estado da Educação, 2012. p. 11-18.

PREFEITURA DE CARIACICA. Conselho Municipal de Educação. Resolução $n^{o} 31$. Fixa normas para a educação básica no sistema municipal de ensino do município de Cariacica. Cariacica: Conselho Municipal de Educação, 2008.

Secretaria Municipal de Educação. Conselho Municipal de Educação. Resolução $n^{o}$ 4. Fixa normas para a educação especial no sistema municipal de ensino do município de Cariacica. Cariacica: Secretaria Municipal de Educação, 2006.

Censo Escolar Interno da Rede Municipal de Cariacica. Cariacica: Secretaria Municipal de Educação, 2016.

REZENDE, V.M.; ISOBE, R.M.R.; MOREIRA, F.A. Investigação comparada em educação: aspectos teóricos e metodológicos. Educação e Politicas em Debate, Uberlândia, v. 2, n. 1, jan./jul. 2013.

SOUZA SANTOS, Boaventura. A gramática do tempo: para uma nova cultura política. 2. ed. São Paulo: Cortez, 2008. 
VIEIRA, S.A.A. Política estadual de educação especial no Espirito Santo: cartografando espaços locais. 192f. Tese (Doutorado em Educação) - Programa de Pós-Graduação em Educação, Universidade Federal do Espírito Santo, Vitória, 2018.

\section{NOTAS}

1. A partir da Política Nacional de Educação Especial em uma perspectiva inclusiva, de 2008, os alunos passaram a frequentar as instituiçōes somente para o atendimento educacional especializado, no contraturno da matrícula no ensino regular.

2. Ver equipamentos em Manual de orientação: Programa de Implantação de Sala de Recursos Multifuncionais (BRASIL, 2010).

3. Estudantes do curso de Pedagogia.

Recebido em 15 de maio de 2018.

Aprovado em 02 de agosto de 2018. 